\title{
Pembinaan Olimpiade Sains Nasional (OSN) Matematika Jenjang SMP Kabupaten Lombok Tengah
}

\author{
${ }^{1}$ Yuntawati, ${ }^{2}$ Sanapiah \\ ${ }^{1,2}$ Prodi Pendidikan Matematika, FSTT, Universitas Pendidikan Mandalika, Jl. Pemuda No. \\ 59A, Mataram, Indonesia 83125
}

EmailKorespondensi: yuntawati@ikipmataram.ac.id

\begin{tabular}{|c|c|}
\hline Art & $c t$ \\
\hline $\begin{array}{l}\text { Article History } \\
\text { Received: } 2020-10-12 \\
\text { Revised: } 2020-10-19 \\
\text { Published: } 2020-10-30\end{array}$ & \multirow{2}{*}{$\begin{array}{l}\text { Development of the National Science Olympiad (OSN) Mathematics for } \\
\text { Junior High School in Central Lombok Tengah. Three students from three } \\
\text { partner schools in Central Lombok Regency, namely SMPN } 1 \text { Praya, SMPN } 5 \\
\text { Kopang, and SMPN } 10 \text { Pujut participated in the training activities for the SMP } \\
\text { mathematics OSN. The place for the implementation of the math Olympiad } \\
\text { coaching activities is at SMPN } 1 \text { Praya, Central Lombok. The mathematics } \\
\text { OSN coaching was carried out, the implementing team held internal } \\
\text { discussions with the OSN supervisor teachers from partner schools regarding } \\
\text { the cognitive deficiencies and weaknesses of the Olympic students. This OSN } \\
\text { coaching was held for } 6 \text { meetings. The OSN coaching activities are } \\
\text { summarized in } 4 \text { stages, namely, (1) analyzing material that is difficult for } \\
\text { partner students, (2) practicing math Olympiad questions, (3) explaining } \\
\text { material that has not been applied, (4) reflecting and evaluating the process of } \\
\text { coaching and evaluating students. which has been carried out at the previous } \\
\text { meeting. The conclusions reached from this service activity include 1) } \\
\text { Mathematics OSN coaching activities by lecturers can improve the ability of } \\
\text { Olympiad participants in solving OSN questions with intensive coaching, and } \\
\text { 2) Mathematics OSN coaching activities by lecturers can deepen the } \\
\text { mathematics knowledge of previous Olympiad participants. still not enough. }\end{array}$} \\
\hline $\begin{array}{l}\text { Keywords } \\
\text { National } \\
\text { Olympiad } \\
\text { Mathematics }\end{array}$ & \\
\hline Info & Abstrak \\
\hline $\begin{array}{l}\text { Sejarah Artikel } \\
\text { Diterima: } 12-10- \\
\text { Direvisi: } 19-10-2 \\
\text { Dipublikasi: } 30-1\end{array}$ & \multirow{2}{*}{$\begin{array}{l}\text { Kegiatan pembinaan OSN matematika SMP ini diikuti oleh tiga siswa siswi } \\
\text { dari tiga sekolah mitra di Kabupaten Lombok Tengah yaitu, SMPN } 1 \text { Praya, } \\
\text { SMPN } 5 \text { Kopang, dan SMPN } 10 \text { Pujut. Adapun tempat pelaksanaan kegiatan } \\
\text { pembinaan olimpiade matematika SMP dilaksanakan di SMPN } 1 \text { Praya } \\
\text { Lombok Tengah. Pembinaan OSN matematika dilaksanakan, tim pelaksana } \\
\text { melakukan diskusi internal dengan Guru Pembina OSN dari sekolah-sekolah } \\
\text { mitra untuk mendiskusikan kekurangan dan kelemahan kognitif siswa peserta } \\
\text { olimpiade. Pembinaan OSN ini dilaksanakan selama } 6 \text { kali pertemuan. } \\
\text { Kegiatan pembinaan OSN terangkum dalam } 4 \text { tahap yaitu, (1) analisis materi } \\
\text { yang menjadi kesulitan siswa mitra, (2) latihan soal-soal olimpiade matematika, } \\
\text { (3) penjelasan materi yang belum dipahami, (4) refleksi dan evaluasi proses } \\
\text { pembinaan dan pencapaian siswa yang sudah dilaksanakan pada pertemuan } \\
\text { sebelumnya. Kesimpulan yang dicapai dari kegiatan pengabdian ini antara lain } \\
\text { 1) Kegiatan pembinaan OSN matematika oleh Dosen dapat meningkatkan } \\
\text { kemampuan peserta olimpiade dalam menyelesaikan soal-soal OSN dengan } \\
\text { pembinaan yang intensif, dan 2) Kegiatan pembinaan OSN matematika oleh } \\
\text { Dosen dapat memperdalam pengetahuan matematika peserta olimpiade yang } \\
\text { sebelumnya masih kurang. }\end{array}$} \\
\hline $\begin{array}{l}\text { K } \\
\mathrm{O} \\
\mathrm{M} \\
\mathrm{M}\end{array}$ & \\
\hline \multicolumn{2}{|c|}{$\begin{array}{l}\text { Sitasi: Yuntawati \& Sanapiah (2020) Pembinaan Olimpiade Sains Nasional (OSN) Matematika } \\
\text { Jenjang SMP Kabupaten Lombok Tengah Sasambo: Jurnal Abdimas (Journal of Community } \\
\text { Service). 2(3), 172-179. DOI : 10.36312/sasambo.v2i3.304 }\end{array}$} \\
\hline
\end{tabular}




\section{PENDAHULUAN}

Departemen Pendidikan Nasional melalui Direktorat Jenderal Manajemen Pendidikan Dasar dan Menengah telah memfasilitasi kegiatan-kegiatan yang mengarah pada kreativitas siswa dalam bidang ilmu pengetahuan dan teknologi melalui berbagai lomba, festival, dan olimpiade (Wesnawa, dkk., 2019). Salah satu Olimpiade bergengsi di tanah air adalah Olimpiade Sains Nasional(OSN).OSN merupakan ajang berkompetisi dalam bidang sains bagi para siswa pada jenjang SD, SMP, dan SMA di Indonesia. OSN juga merupakan wadah bagi siswa dalam mengimplementasikan Penguatan Pendidikan Karakter (PPK) melalui bidang sains. Peserta Olimpiade Sains Nasional adalah siswa terbaik dari provinsinya masing-masing yang telah lolos seleksi di tingkat kabupaten dan provinsi.

Pelaksanaan Olimpiade Sains Nasional ini didasarkan pada kesuksesan Indonesia sebagai tuan rumah Olimpiade Fisika Internasional (IPhO - International Physics Olympiad) yang diselenggarakan di Bali pada tahun 2002. Sejak tahun 2002 telah dimulai kegiatan Olimpiade Sains Nasional (OSN) untuk siswa SMA/MA yang terdiri dari kompetisi di bidang Matematika, Fisika, Biologi, Kimia dan Informatika/Komputer.

OSN tingkat SMP diadakan sejak tahun 2003. Pada periode 2003 sampai dengan 2009, bidang yang dilombakan pada OSN meliputi tiga bidang utama yaitu Matematika, Biologi, dan Fisika. Pada tahun 2010, Direktorat Pembinaan SMP memasukkan Ilmu Pengetahuan Sosial (IPS) dalam bidang yang dilombakan pada OSN. Sehingga sejak tahun 2010 sampai dengan tahun 2015 bidang OSN yang dilombakan adalah empat bidang. Dengan adanya Kurikulum 2013, bidang Fisika dan Biologi digabungkan menjadi satu bidang yaitu Ilmu Pengetahuan Alam (IPA) pada tahun 2015. Sehingga mulai tahun 2015 bidang lomba meliputi tiga bidang yakni Matematika, IPS, dan IPA (Wesnawa, dkk., 2019).

Perubahan yang terjadi ini dimaksudkan untuk memotivasi dan menumbuhkembangkan atmosfer kompetisi serta mendorong pihak-pihak yang berwenang untuk memberikan ruang belajar, memfasilitasi dan menstimulus para siswa dan guru yang berprestasi dan memiliki bakat minat pada sains agar meningkatkan kemampuan akademisnya dengan berpartisipasi pada OSN SMP.Menteri Pendidikan dan Kebudayaan (Mendikbud) Mohammad Nuh menyampaikan alasan kementerian tetap menggelar dan memperkuat penyelenggaraan Olimpiade Sains Nasional (OSN)adalah untuk menciptakan atmosfir, membangun budaya dan tradisi yang berbasis ilmu pengetahuan (Kompas.com, 2012).

Kemampuan peserta didik di bidang matematika di Indonesia masih cukup rendah, tidak terkecuali Nusa Tenggara Barat. Berdasarkan rekapitulasi perolehan medali OSN bidang studi matematika yang dikeluarkan Kementerian Pendidikan dan Kebudayaan, dari tahun 2017 sampai tahun 2019, NTB tidak pernah masuk didalam daftar penerima medali baik medali emas, perak atupun perunggu (kemdikbud.go.id).

Paradigma ini didukung data perolehan nilai matematika pada Trends in International Mathematics and Science Study (TIMSS) yang masih rendah.Pada TIMSS 2011, Indonesia menempati posisi ke-6 dibawah Negara tetangga seperti Malaysia, Thailand, dan Singapura (Rosnawati, 2013).Berdasarkan penelitian yang dilakukan oleh PISA menunjukkan hampir tidak ada (mendekati $0 \%$ ) siswa di Indonesia yang berada pada kemampuan matematika level 6, bahkan hampir $80 \%$ siswa masih berada pada kemampuan matematika level 1 dari 6 level yang ditetapkan (Yuntawati, 2017). Data ini memberi gambaran bahwa matematika merupakan pelajaran yang sulit.

Matematika yang merupakan salah satu bidang dalam OSN dianggap sulit karena menyajikan permasalahan-permasalahan matematika yang memerlukan analisis dan kemampuan berpikir tingkat tinggi. Sanapiah, Kurniawan, Yuntawati (2020) menyajikan data jumlah peserta OSN 6 kabupaten di Nusa Tenggara Barat yang mampu menjawab lebih dari 40 soal dengan benar hanya 6 orang dari 68 peserta. Hal ini menunjukkan bahwa siswa yang diikutsertakan OSN harus mendapatkan pembinaan khusus OSN. 
Banyak sekolah menengah pertama di NTB telah melaksanakan kegiatan pembinaan olimpiade terhadap peserta didiknya di berbagai bidang pelajaran, termasuk bidang matematika. Akan tetapi, keberhasilannya masih belum bisa dikatakan maksimal. Mandailina \& Syaharuddin (2018) menyatakan bahwa perlu dilakukan pembinaan lebih lanjut terkait materi olimpiade, karena mengingat penyampaian materi di tingkat SMP/M.Ts sangat minim.Permasalahan ini memerlukan perhatian semua pihak terkait, baik sekolah, pemerintah daerah, maupun perguruan Tinggisebagai pihak yang memiliki sumber daya manusia yang profesional di bidang pendidikan.

Beberapa pelatihan telah dilakukan diantaranya pembinaan yang dilakukan oleh Mandailina \& Syaharuddin (2018) dengan tujuan untuk meningkatkan kemampuan siswa dalam menyelesaikan soal olimpiade di SMPN 20 Mataram memberikan progress yang baik sesuai dengan tujuan pembinaan yang ingin dicapai. Demikian juga pelatihan penyusunan tes keterampilan proses sains di SMPN 20 Mataram yang dilakukan oleh Artayasa, dkk. (2019) menunjukkan bahwa guru di SMPN 20 Mataram menjadi lebih mengenal karakteristik tes dan teknik pengembangan tes olimpiade sains.

Berkaca dari hasil positif yang telah dicapai dalam beberapa kegiatan pembinaan di atas, UNDIKMA sebagai salah satu Perguruan Tinggi yang bertanggung jawab pada peningkatan mutu pendidikan, bekerjasama dengan pemerintah kabupaten Lombok Tengah berusaha berpartisipasi dengan mengirimkan dosen-dosen Program Studi Pendidikan Matematikauntuk membantu guru-guru bidang studi tersebut mempersiapkan siswa peserta OSN Provinsi NTB jenjang SMP khususnya di Kabupaten Lombok Tengah. Selain Program Studi Pendidikan Matematika, UNDIKMA juga mengirimkan dosen dari Program Studi Pendidikan Fisika, Kimia, dan Biologi.

Kegiatan pengabdian ini bertujuan untuk meningkatkan kemampuan peserta olimpiade dalam menyelesaikan soal-soal OSN. Sebagai dosen Program Studi Pendidikan Matematika,tim pelaksana ditugaskan untuk membantu guru matematika membina siswa peserta olimpiade matematika yang telah lulus seleksi dan menjadi juara I, II, dan III Olimpiade Sains Nasional (OSN) tingkat kabupaten agar bisa berkompetisi dalam Olimpiade Sains Nasional (OSN) tingkat Provinsi.

\section{METODE}

\section{Solusi Permasalahan}

Solusi permasalahan pembinaan Olimpiade Sain Nasional (OSN) yang masih belum terorganisir dengan baik yang dilakukan oleh guru-guru SMP di NTB terutama di kabupaten Lombok tengah adalah melibatkan perguruan Tinggi sebagai pihak yang mencetak caloncalon guru SMP yang berkualitas. Keterbatasan tenaga Pembina yang ada di sekolah membutuhkan pembinaan dan pendampingan pendidikan tinggi yang memiliki konsentrasi pada bidang yang dikompetisikan.

Sebelum pembinaan OSN matematika dilaksanakan, tim pelaksana melakukan diskusi internal dengan guru-guru Pembina OSN dari sekolah-sekolah mitra untuk mendiskusikan kekurangan dan kelemahan kognitif siswa peserta olimpiade. Para guru Pembina olimpiade dari sekolah mitra juga berbagi temuan dan pengalaman selama membina OSN.

Pembinaan OSN ini dilaksanakan selama 6 kali pertemuan. Kegiatan pembinaan OSN terangkum dalam 4 tahap yaitu, (1) analisis materi yang menjadi kesulitan siswa mitra, (2) latihan soal-soal olimpiade matematika, (3) penjelasan materi yang belum dipahami, (4) refleksi dan evaluasi proses pembinaan dan pencapaian siswa yang sudah dilaksanakan pada pertemuan sebelumnya. Rangkaian tahap 1 sampai tahap 3 diberikan pada pertemuan ke-1, ke-2, ke-4, dan ke-5. Sedangkan tahap 4 diberikan pada pertemuan ke-3 dan ke-6. 


\section{Metode \& Prosedur Pemecahan Masalah}

Kegiatan pengabdian kepada masyarakat yang berupa pembinaan siswa peserta Olimpiade Sain Nasional (OSN) matematika SMP terorganisir dalam suatu rangkaian kegiatan yang terbagi menjadi dua kegiatan yaitu diskusi internal guru Pembina olimpiade matematika dari sekolah mitra dengan dosen selaku tim pelaksana Pembinaan OSN matematika; dan pelaksanaan pembinaan OSN matematika SMP.

Adapun pelaksanaan pembinaan OSN Matematika SMP terangkai dalam beberapa tahapan kegiatan seperti yang terlihat dalam diagram berikut:

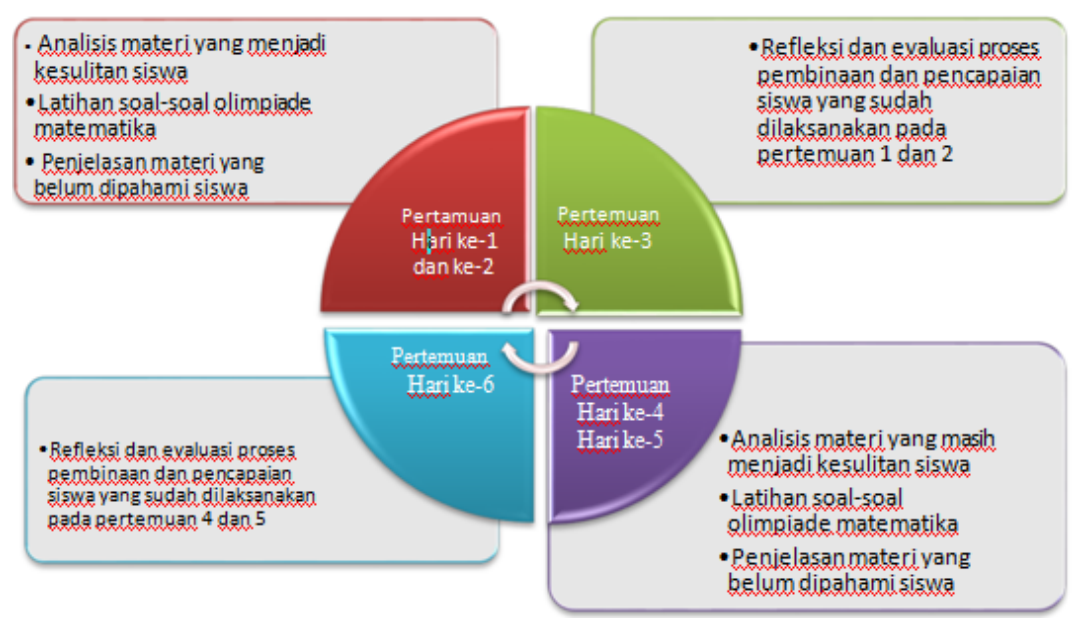

Diagram 1. Rangkaian Pelaksanaan Kegiatan Pembinaan OSN

Kegiatan pembinaan OSN SMP ini diikuti oleh Sembilan siswa siswi dari enam sekolah mitra di Kabupaten Lombok Tengah yaitu, SMPN 1 Praya, SMPN 2 Praya, SMPN2 Kopang, SMPN 5 Kopang, SMPN 1 Jonggat, dan SMPN 10 Pujut (Diagram 3).

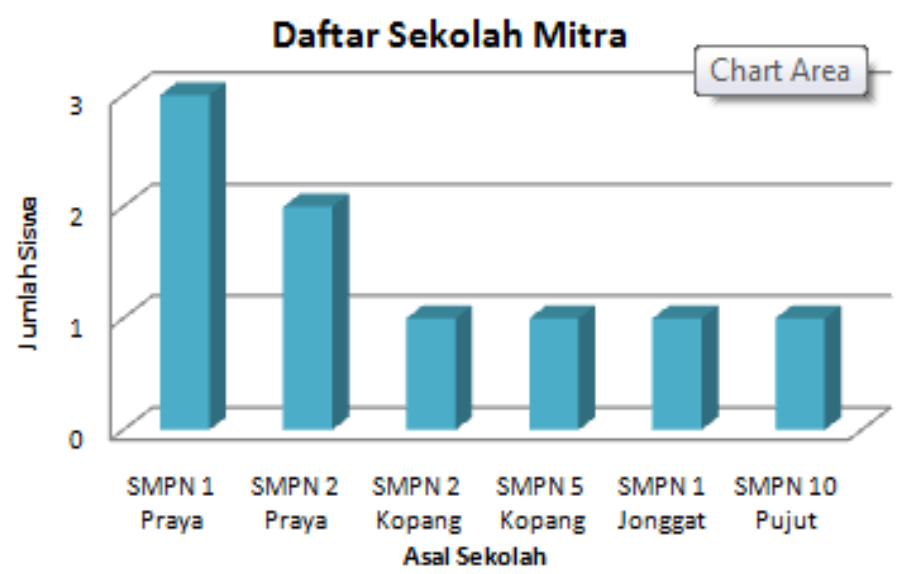

Diagram 2. Daftar peserta siswa OSN Binaan

Tiga dari sembilan siswa peserta OSN fokus mengikuti pembinaan bidang matematika dari 3 sekolah berbeda yaitu SMPN 1 Praya, SMPN 5 Kopang, dan SMPN 10 Pujut. Sedangkan sisa fokus pada bidang IPA, dan IPS. Adapun tempat pelaksanaan kegiatan pembinaan olimpiade matematika SMP dilaksanakan di SMPN 1 Praya Lombok Tengah.

\section{Partisipasi Mitra}

Guru-guru Pembina olimpiade matematika SMP dari sekolah mitra berpartisipasi dalam mengantarkan siswa binaannya ke SMPN 1 Praya Lombok Tengah yang merupakan tempat pelaksanaan kegiatan pembinaan OSN matematika. Tidak hanya mengantarkan, para guru Pembina olimpiade juga berdiskusi berbagi temuan dan pengalaman selama membina siswa binaannya hingga meraih juara I, II, dan III OSN matematika tingkat Kabupaten. Proses didkusi dilakuikan dengan wawancara tak terstruktur dengan masing-masing guru 
pembina tiap sekolah mitra. Selanjutnya pada kegiatan pelaksanaaan pembinaan OSN matematika yang berpartisipasi hanya siswa peserta OSN matematika dari sekolah mitra dan dosen program studi pendidikan matematika selaku tim pelaksana pembinaan OSN matematika SMP.

\section{HASIL DAN PEMBAHASAN}

Kegiatan pengabdian ini terangkai dalam dua kegiatan yaitu, diskusi internal guru Pembina olimpiade matematika dari sekolah mitra dengan dosen selaku tim pelaksana Pembinaan OSN matematika; dan pelaksanaan pembinaan OSN matematika SMP.

\section{A. Diskusi internal Guru Pembinadan Dosen Pembina OSN matematika}

Diskusi internal Guru dan Dosen Pembina OSN matematika dilakukan sebelum kegiatan pembinaan OSN matematika dilaksanakan. Berdasarkan hasil wawancara tak terstruktur dengan Guru Pembina, diperoleh berbagai temuan tentang pengalaman guru selama membina peserta olimpiade dalam beberapa tahun sebelumnya. Temuan-temuan hasil diskusi internal terangkum sebagai berikut:

1. Dasar pengetahuan peserta olimpiade sudah cukup memenuhi syarat minimal yang dinyatakan dalam bentuk nilai matematika (wajib dan peminatan) tidak kurang dari 80.Hanya saja peserta terkadang belum bisa menerapkan konsep yang dimiliki didalam pemecahan masalah.

2. Kemampuan penalaran dan analisis peserta olimpiade sudah cukup bagus hanya saja mereka sering lupa rumus,

3. Peserta olimpiade perlu diberikan drill latihan soal olimpiade yang beragam

4. Peserta olimpiade masih kurang menguasai materi Geometri,Statistik, dan Peluang.

Berdasarkan temuan hasil diskusi internalGurupembina dan Dosen pembina, dapat disimpulkan bahwa guru Pembina olimpiade perlu meningkatkan dan menyegarkan kembali pengetahuannya tentang soal-soal olimpiade dan kreatifitas pemecahan masalah sehingga mudah diterima siswa. Muliani (2018) mengemukakan bahwa peningkatan kompetensi professional guru matematika terutama guru Pembina olimpiade matematika sangat diperlukan untuk menunjang peningkatan prestasi sekolah khususnya bidang olimpiade sains. Hal ini berimbas pada kemampuan peserta binaan OSN yang masih belum memenuhi standar minimal yang diharapkan.Sehingga perlu dilakukan tindakan lebih lanjut untuk membantu menguatkan kompetensi siswa dalam ajang olimpiade tingkat Propinsi NTB.

\section{B. Pelaksanaan pembinaan OSN matematika SMP}

Kegiatan pembinaan OSN terangkum dalam 4 tahap yaitu, (1) analisis materi yang menjadi kesulitan siswa mitra, (2) latihan soal-soal olimpiade matematika, (3) penjelasan materi yang belum dipahami, (4) refleksi dan evaluasi proses pembinaan dan pencapaian siswa yang sudah dilaksanakan pada pertemuan sebelumnya. Rangkaian tahap 1 sampai tahap 3 diberikan pada pertemuan ke-1, ke-2, ke-4, dan ke-5. Sedangkan tahap 4 diberikan pada pertemuan ke-3 dan ke-6.

1. Analisis Kesulitan, Latihan Soal, dan Pendalaman Materi Matematika

Kegiatan pembinaan olimpiade matematika dilaksanakan selama enam kali pertemuan yang dimulai tanggal 9 April 2018 dan berakhir pada tanggal 14 April 2018. Proses analisis, latihan soal, dan pendalaman materi matematika dilakukan pada pertemuan pertama, kedua, keempat, dan kelima.Yuntawati, dkk. (2020) mengemukakan bahwa mengidentifikasi dan menganalisis kesulitan siswa sangat penting untuk meningkatkan kualitas mengajar sekaligus mengatasi kesulitan belajar tersebut. Identifikasi kesulitan belajar siswa menjadi langkah awal untuk menyusun rencana perbaikan.

Analisis kesulitan siswa terhadap materi olimpiade matematika dilakukan pada pertemuan pertama. Hal ini dilakukan untuk mendapatkan informasi lanjutan tentang 
kesulitan yang dirasakan secara langsung dari peserta olimpiade.Dosen Pembina menggali informasi dalam proses Tanya jawab dengan siswa peserta olimpiade. Berikut beberapa kesulitan yang dihadapi siswa pada saat mempelajari, dan menyelesaikan soal matematika, 1) Siswa sering lupa rumus, 2) Siswa kesulitan memahami soal-soal olimpiade, dan 3) Pada beberapa materi, siswa kurang menguasai dan memahaminya.

Selanjutnya Dosen Pembina mencoba memberikan beberapa contoh soal olimpiade matematika untuk diselesaikan setiap peserta. Dari beberapa soal yang diselesaikan terlihat bahwa siswa memahami konsep matematika yang harus dipakai dalam menyelesaikan soal, hanya saja terkadang siswa membutuhkan waktu yang cukup lama untuk bisa mengingat dan menggunakannya dalam menyelesaikan soal.

Pada pertemuan selanjutnya yaitu pertemuan kedua, Dosen Pembina memberikan latihan soal-soal olimpiade matematika yang telah diklasifikasikan berdasarkan materinya. Hal ini dilakukan dengan tujuan agar siswa terbiasa dan fokus dengan variasi model-model soal pada satu materi. Pengklasifikasian soal berdasarkan materinya ini juga membantu mempermudah Dosen Pembina dalam menjelaskan materi secara lebih mendalam ketika ditemukan kesulitan dalam proses menyelesakan soal Olimpiade. Tidak hanya menjawab dengan benar soal yang diberikan, peserta olimpiade juga diminta untuk menjelaskan hasil jawabannya. Marpaung (2018) menyatakan bahwa diskusi dan presentasi dapat menumbuhan rasa percaya diri karena didalam proses pembelajaran tersebut memungkinkan kemunculan berbagai kemampuan seperti kemampuan menganalisis masalah, kemampuan berpendapat serta kemampuan untuk mempertahankan pendapatnya.Pemberian latihan soal ini dilanjutkan pada pertemuan keempat dan kelima yang sebelumnya yaitu pada pertemuan ketiga dilakukan refleksi dan evaluasi proses pembinaan dan pencapaian siswa selama pertemuan pertama dan kedua.

Pada pertemuan kelima, sebelum Dosen Pembina memberikan latihan soal-soal olimpiade matematika, Dosen Pembina kembali menggali informasi kesulitan yang dialamisiswa dalam menyelesaikan soal-soal olimpiade melalui proses Tanya jawab dan memberikan masukan, nasehat, dan juga solusi kepada siswa.

2. Refleksi dan Evaluasi Proses Pembinaan Olimpiade Matematika

Berdasarkan hasil pengamatan selama proses pembinaan, masih ditemukan kekurangan-kekuangan, sehigga perlu dilakukan refleksi. Refleksi proses pembinaan olimpiade matematika dilakukan pada pertemuan ketiga dan keenam. Hal ini dilakukan untuk melihat kekurangan-kekurangan selama proses pembinaan dan merancang tindakan perbaikannya. Faizin, (2018) menyebutkan bahwa refleksi dilakukan untuk mengevaluasi seluruh aktivitas pembelajaran dan hasil-hasil yang diperoleh untuk selanjutnya menemukan manfaat langsung maupun tidak langsung dari pembelajaran yang telah berlangsung. Pada pertemuan ketiga dan keenam ini tidak hanya dilakukan refleksi, tapi juga dilakukan evaluasi untuk melihat pencapaian siswa dan kesiapan siswa dalam menghadapi olimpiade.

Kekurangan-kekurangan pada pertemuan pertama, dan kedua serta rencana tindakan perbaikannya terangkum pada tabel 1 berikut:

Tabel 1. Kekurangan dan rencana tindakan perbaikan pertemuan ke-1, dan k e-2

\begin{tabular}{lll}
\hline No. & Kekurangan & Rencana Tindakan Perbaikan \\
\hline 1 & $\begin{array}{l}\text { Soal-soal olimpiade matematika yang } \\
\text { diberikan Dosen Pembina banyak yang telah }\end{array}$ & $\begin{array}{l}\text { Mencari soal-soal olimpiade terbaru } \\
\text { dari sumber-sumber yang belum }\end{array}$ \\
diketahui siswa dan sudah pernah dikerjakan & $\begin{array}{l}\text { ditelusuri oleh siswa } \\
\text { Jawaban dan penjelasan Dosen Pembina } \\
\text { disampaikan secara lisan dan melalui } \\
\text { coretan-coretan buram yang acak sehingga } \\
\text { siswa kesulitan merekamnya }\end{array}$ & $\begin{array}{l}\text { Menyediakan kunci jawaban yang } \\
\text { sudah ditulis rapi untuk bisa dipelajari } \\
\text { kembali oleh siswa }\end{array}$ \\
3 & $\begin{array}{l}\text { Dosen Pembina kurang memperhatikan } \\
\text { Membagi Dosen Pembina menjadi dua }\end{array}$
\end{tabular}


perbedaan kemampuan masing-masing siswa

$4 \quad$ Hasil evaluasi siswa kurang memuaskan dan masing-masing membina siswa berdasarkan kemampuannya Dosen Pembina lebih memperhatikan waktu dan tidak menyia-nyiakan waktu untuk obrolan yang kurang bermanfaat

Semua rencana tindakan perbaikan yang telah disusun berdasarkan kekurangankekurangan pada pertemuan pertama dan kedua dilaksanakan pada pertemuan keempat dan kelima. Selanjutnya refleksi dan evaluasi kembali dilakukan pada pertemuan terakhir yaitu pertemuan keenam.

Kekurangan pada pertemuan keempat dan kelima sudah semakin berkurang. Siswa sudah semakin fokus menyelesaikan soal karena soal-soal olimpiade matematika yang mereka terima belum pernah mereka lihat dan kerjakan. Dosen Pembina juga semakin mudah menjelaskan proses penyelesaian tiap soal karena sudah ada kunci jawaban yang tersusun rapi dan jelas. Hasil evaluasi yang dicapai siswa juga jauh lebih memuaskan dengan nilai matematika (wajib dan peminatan) tidak kurang dari 80 .

Berikut ini beberapa dokumentasi kegiatan pembinaan Olimpiade Sains Nasional (OSN) bidang matematika jenjang SMP:
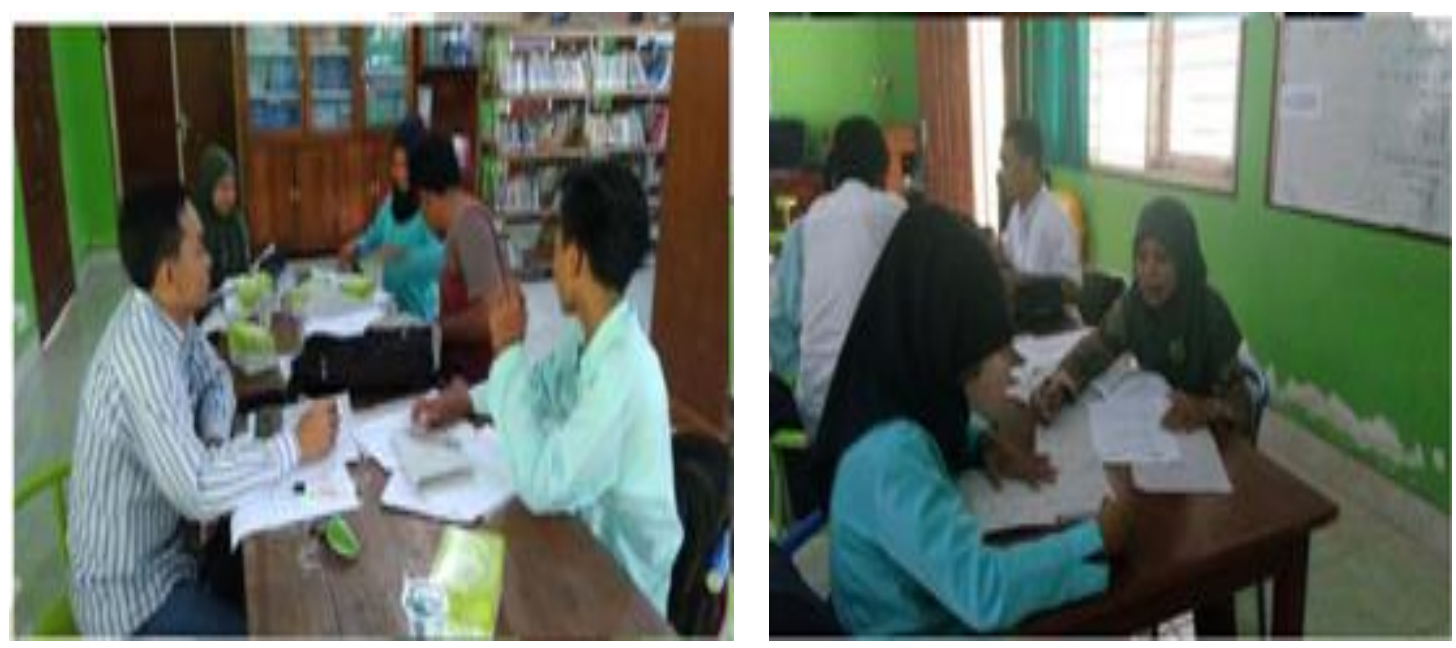

Gambar 1. Dokumentasi proses pembinaan OSN Matematika SMP

\section{KESIMPULAN}

Berdasarkan hasil pelaksanaan kegiatan pembinaan OSN matematika SMP ini dapat ditarik kesimpulan bahwa:

1. Kegiatan pembinaan OSN matematika oleh Dosen dapat meningkatkan kemampuan peserta olimpiade dalam menyelesaikan soal-soal OSN dengan pembinaan yang intensif.

2. Kegiatan pembinaan OSN matematika oleh Dosen dapat memperdalam pengetahuan matematika peserta olimpiade yang sebelumnya masih kurang.

\section{SARAN}

Berdasarkan temuan selama proses pembinaan, dapat diberikan saran sebagai berikut:

1. Guru-guru Pembina olimpiade di sekolah dalam membina olimpiade diharapkan tidak hanya memberikan latihan soal, tapi juga perlu melakukan analisis kesulitan belajar siswa peserta olimpiade.

2. Guru-guru Pembina olimpiade di sekolahdiharapkan dapat meningkatkan kompetensi profesionalnya sehingga dapat menunjang kompetensi siswa binaannya 


\section{DAFTAR PUSTAKA}

Direktorat Pembinaan Sekolah Menengah Pertama. (2017). Petunjuk Pelaksanaan OlimpiadeSains Nasional (OSN) Sekolah Menengah Pertama Tahun 2018. Jakarta

Faizin, K. (2018). Pemanfaatan Jurnal Refleksi Sebagai Strategi Metakognitif Dalam Meningkatkan Keaktifan dan Hasil Belajar Matematika. Lentera Pendidikan, 20 (1), 33-47: journal.uin-alauddin.ac.id

Kemdikbud.go.id.https://www.google.com/search?client=firefox-b$\mathrm{d} \& \mathrm{q}=$ rekapitulasi+perolehan+medali+osn+smp

Marpaung, D. (2018) Penerapan Metode Diskusi dan Presentasi untuk Meningkatkan Minat dan Hasil Belajar Siswa Kelas XI IPS-1 SMA Negeri 1 Bagan Sinembah. SEJ (School Education Journal), 8 (4), 360-368: http://jurnal.unimed.ac.id

Muliani, F., Noviati, D., Fajriani, F. (2018). Pembinaan Peningkatan Mutu Pendidikan Bidang Olimpiade Sains Bagi Guru SD Kota Langsa Provinsi Aceh. Jurnal ABDIMAS Unmer Malang, 3 (2), 9-13: https://www.google.com/url?sa=t\&rct=j\&q=\&esrc=s\&source=web\&cd=\&cad=rja\&uac $\mathrm{t}=8 \&$ ved=2ahUKEwj7hXDtavsAhVMbysKHd7rASIQFjACegQIAhAC\&url=http\%3A $\% 2 \mathrm{~F} \% 2$ Fjurnal.unmer.ac.id\%2Findex.php\%2Fjpkm\%2Farticle\%2Fdownload\%2F2586 \%2F1573\&usg=AOvVaw3vgYQJfntLKomREPiZKhyG

Sanapiah, S., Kurniawan, A., Yuntawati, Y. (2020). Profil Kemampuan Siswa Peserta Olimpiade Matematika Dalam Menjawab Soal Pilihan Ganda. Jurnal Media Pendidikan Matematika, $\quad 8 \quad$ 7886:http://ojs.ikipmataram.ac.id/index.php/jmpm/article/download/2739/1976

Wesnawa, I. G. A., Christiawan, P. I., Lasmawan, W., Dewi, N. A. W. T., \& Sulindawati, L. G. E. (2019). Kolaborasi Pembinaan Siswa dalam Persiapan OSN Menuju Prestasi Unggul Di SMP Negeri 1 Singaraja. Prosiding SENADIMAS Ke-4. https://lppm.undiksha.ac.id/senadimas2019/

Wiworo. 2018. OSN Bidang Matematika SMP/MTs. Pusat Pengembangan dan Pemberdayaan Pendidik dan Tenaga Kependidikan Matematika. Yogyakarta:SAI Global: https://docplayer.info/32358809-Olimpiade-sains-nasional-matematika-smp.html

Yuntawati, Y. Aziz, L.A., Agustin, W. (2020). Pendampingan guru BAIK (Belajar, Aspiratif, Inklusif, Kontekstual). SASAMBO: Jurnal Abdimas (Journal of Community Service), 2 (2),

http://jurnalcenter.litpam.com/index.php/Sasambo_Abdimas/article/view/213/87 